\title{
The use of religious/spiritual coping among patients with cancer undergoing chemotherapy treatment
}

\author{
Ana Cláudia Mesquita ${ }^{1}$ \\ Érika de Cássia Lopes Chaves ${ }^{2}$ \\ Carolina Costa Valcanti Avelino ${ }^{3}$ \\ Denismar Alves Nogueira² \\ Raquel Gerhke Panzini ${ }^{4}$ \\ Emilia Campos de Carvalho
}

Objective: to investigate the use of religious/spiritual coping among people with cancer undergoing chemotherapy. Methods: a quantitative, descriptive and cross-sectional study of 101 patients undergoing intravenous chemotherapy in an oncology outpatients center in a public hospital in Minas Gerais, made in the first semester of 2011. For data collection, an interview was held, using a questionnaire for characterizing the sample and the Brief Spiritual/Religious Coping Scale. Results: all subjects made use of religious/spiritual coping (mean=3.67; sd=0.37); the younger individuals, those with no religion and those who consider spiritual support unimportant tend to use coping negatively; individuals who would like to receive spiritual support and who participate in support groups for cancer patients, on the other hand, use coping positively. Conclusions: the study reinforces that religious/spiritual coping is an important strategy for coping with cancer, and contributes to an understanding of the same as a useful tool for spiritual care.

Descriptors: Nursing; Spirituality; Drug Therapy; Neoplasms.

\footnotetext{
${ }^{1}$ Doctoral student, Escola de Enfermagem de Ribeirão Preto, Universidade de São Paulo, WHO Collaborating Centre for Nursing Research Development, Ribeirão Preto, SP, Brazil.

2 PhD, Adjunct Professor, Escola de Enfermagem, Universidade Federal de Alfenas, Alfenas, MG, Brazil.

${ }^{3}$ RN, Resident in Family Health, Escola de Enfermagem, Universidade Federal de Alfenas, Alfenas, MG, Brazil.

${ }^{4}$ Doctoral Student, Universidade Federal do Rio Grande do Sul, Porto Alegre, RS, Brazil.

${ }^{5}$ PhD, Full Professor, Escola de Enfermagem de Ribeirão Preto, Universidade de São Paulo, WHO Collaborating Centre for Nursing Research Development, Ribeirão Preto, SP, Brazil.
} 


\section{Introduction}

Epidemiological studies carried out in recent decades have indicated a positive relationship between spirituality and religiosity and better health indicators ${ }^{(1)}$. Spirituality may be understood as a person's essence, a search for meaning and purpose in life, while religion may be defined as a partial expression of spirituality, practiced through sacred traditions transmitted through cultural heritage, accompanied by dogma and doctrines $^{(2)}$

Religious people frequently present a greater capacity for coping with adverse circumstances in life through their use of religious/spiritual coping (RSC) ${ }^{(1)}$. Coping refers to a set of cognitive and behavioral strategies, used with the aim of coping with stressful situations(3). When the patient uses religious resources for this purpose, he/she is using religious coping(4). Although some definitions of religious coping do not explicitly mention spirituality, this too constitutes an important coping resource(3).

RSC may be positive or negative ${ }^{(5)}$; when positive (PRSC), it includes strategies which afford the individual a beneficent effect, such as seeking the love/protection of God, or a greater connection with transcendental forces. Negative RSC (NRSC) involves strategies which create prejudicial consequences - such as redefining the stressor as divine punishment ${ }^{(3)}$. Of the instruments used for measuring, the Brief Spiritual/Religious Coping Scale (Brief-SRCOPE scale) was used in this study(6). This determines Total RSC (TRSC), which indicates the total quantity of RSC practiced by the individual, through the average between the PRSC rate and the average of the responses of the Inverted NRSC(6). TRSC and NRSC are associated with better health results and quality of life(3).

In the last decade, greater attention has been given to spirituality and its role as a coping strategy used by patients with cancer; after all, spirituality - and religion too - have been shown to be important in coping with this disease, through performing a protective role against psychological morbidity, due to their important impact on how the person deals with the illness ${ }^{(7-8)}$. Each individual expresses spirituality in his or her own way, relating it to the hope of surviving the cancer, considering that this disease causes fear and that spirituality renews, which demonstrates the importance of the same as a coping strategy in planning care for the patient with cancer $^{(9)}$. It follows that it is necessary to deepen health professionals' knowledge regarding the patient's spiritual dimension, thus increasing their ability to relieve human suffering ${ }^{(10)}$, which justifies the investment in studies of this issue.

In clinical practice, it is essential for the nurse to learn about the patient's spiritual dimension in planning the nursing care, considering that when used as a method of coping, spirituality occupies a salient position in peoples' lives $^{(9)}$.

This study's objective is to investigate the use of religious/spiritual coping among people with cancer, undergoing chemotherapy.

\section{Methods}

This is a quantitative, descriptive and crosssectional study, approved by the Research Ethics Committee under protocol 107/2010, in line with directives for undertaking research involving human beings. The study population was made up of patients with cancer undergoing intravenous chemotherapy in a public oncology outpatient center in the state of Minas Gerais, attended in the first semester of 2011. The sample, characterized by convenience was composed of 101 patients (approximately $50 \%$ of the population), attended in the morning period. It included the patients who were undertaking intravenous chemotherapy treatment, who were aged 21 or over, of both sexes, who were orientated in space, time and person and were able to express themselves verbally. After being invited to participate in the study and agreeing, all signed the terms of Free and Informed Consent.

A questionnaire and the Brief-SRCOPE scale were used for data collection. The questionnaire (authored by the researchers) was constructed with the aim of characterizing the participants according to demographic, clinical and spiritual/religious aspects; it was submitted to face and content validation by three judges who study spirituality/religiosity and oncological disease. All the suggestions were incorporated and related to how the questionnaire was presented.

The Brief-SRCOPE Scale is a brief version of the RSC Scale validated for Brazil(6), adapted from the NorthAmerican instrument, which contains 105 items $^{(5)}$ and allows the evaluation of use of religious and spiritual strategies in dealing with important stressors in life. The Brief-SRCOPE Scale contains 49 items, 34 related to PRSC and 15 related to $\operatorname{NRSC}^{(11)}$. The responses are given on a Likert-type scale of five points, varying from 1 (never) to 5 (very much), and receive a score that makes it possible to analyse and understand the data. The parameter used for analysis of the values of the Brief-SRCOPE Scale's 
means is: none or negligible (1.00 to 1.50$)$, low (1.51 to 2.50 ), average (2.51 to 3.50 ), high ( 3.51 to 4.50 ) and very high $(4.51 \text { to } 5.00)^{(6)}$. The internal consistency analysis of the Brief-SRCOPE Scale's set of items for the study had a Cronbach alpha of 0.90 , demonstrating significant internal consistency, with a value similar to that obtained in validating the scale, which was $0.97^{(6)}$, especially considering that this study's sample is equivalent to $1 / 6$ of the original sample.

For this study, the questionnaire and the BriefSRCOPE Scale were submitted to a pre-test with 29 patients who were not part of the sample, to check the understanding of the items by the patients. Difficulties in understanding on the part of the patients were not detected.

Data collection was carried out during the chemotherapy sessions; the study's objective was explained, and the subjects' participation requested. After this, with those who consented to participate, an interview was held so that they could respond to the general questionnaire and the Brief-SRCOPE Scale. The researchers chose to interview in order to facilitate individuals' participation, as most of the time the upper limb was punctured for the infusion of the medication, which would make it difficult to respond in writing. It is worth emphasizing that there was no interpretation of the questions to the patients on the part of the interviewers.

Data analysis was preceded by the production of a database using Excel (Windows - 2010), used for coding the variables in a dictionary and for validation through double keying of the data. The Statistical Package for Social Sciences software, version 17.0, was used for statistical analysis. Descriptive statistics allowed the presentation and summarizing of the data obtained. The Spearman correlation coefficient was used to correlate the ordinal variables (age, family income, time since diagnosis, importance given to religion/spirituality) with the RSC. The $t$ test allowed the comparison of the differences of the averages of the RSC values in relation to the different variables (sex, having a religion, considering the giving of spiritual care to be important and wishing to receive spiritual support). The variance analysis made it possible to test the evenness of the responses' averages. The multiple linear regression model was used to explain the relationship between the socio-demographic variables and the scores of the BriefSRCOPE Scale dependent variable (TRSC, PRSC and NRSC). The level of significance established was $5 \%$ for the tests and $10 \%$ for the parameters of the regression model.

\section{Results}

Of the 101 subjects participating, 51 (51\%) are female, $50(50 \%)$ are in the age range 43 to 64 years of age, 60 (59\%) have finished their basic education*, $65(64 \%)$ are married and 56 (57\%) have an income equivalent to two to three minimum salaries (minimum salary: $\mathrm{R} \$ 545.00$, at the time of data collection).

The prevalent types of cancer were: colorectal $(31 \%)$, breast $(17 \%)$ and prostate $(8 \%)$. In relation to length of treatment, $69 \%$ of the patients had received chemotherapy for between 1 and 12 months, $18 \%$ for less than one month, and $11 \%$ for between 1 and 4 years. In relation to time since diagnosis, $64 \%$ of the patients reported having learnt of the illness between 1 and 12 months previously, and $16 \%$ between 13 months and 2 years previously. $80 \%$ of the patients had experienced other types of treatment for cancer: $54 \%$ had had surgery, 5\% radiotherapy and $24 \%$ both treatments. Regarding the presence of side effects of chemotherapy, $37 \%$ of the interviewees stated that they had not experienced side effects, $24 \%$ stated that they experienced mild side effects, $14 \%$ moderate, and $16 \%$ intense; $58 \%$ participated in some support group for patients with cancer.

In relation to the approaching of the issue of spirituality/religion by health professionals, $93 \%$ of the patients consider it to be important as a way of helping in coping with the disease; however, only $16 \%$ stated that they had already spoken with a health professional on the matter. Further, the majority of the subjects $(80 \%)$ stated that they would like to receive some type of spiritual care during the period of treatment.

Table 1 - Distribution of subjects interviewed according to religious and spiritual characteristics, Minas Gerais, Brazil, 2011

\begin{tabular}{lc}
\hline \multicolumn{1}{c}{ Variables } & $\mathbf{n}(\%)$ \\
\hline Religion & \\
Roman Catholic & $86(85)$ \\
Evangelical & $11(11)$ \\
Spiritualist & $02(02)$ \\
No religion, but spiritual & $02(02)$ \\
Importance of religion/spirituality & \\
Not important & 0 \\
A little important & 0 \\
& (continue...)
\end{tabular}

* Basic education in Brazil is from 5 years through to 13. Translator's note. 
Table 1 - (continuation)

\begin{tabular}{lc}
\hline \multicolumn{1}{c}{ Variables } & $\mathbf{n}(\%)$ \\
\hline Important & $24(24)$ \\
Very important & $77(76)$ \\
Church attendance & \\
Daily & $01(01)$ \\
1 or more times per week & $54(53)$ \\
1 or more times per month & $23(23)$ \\
1 time per year & $12(12)$ \\
Never & $09(09)$ \\
Habitually pray/meditate & \\
Yes & $101(100)$ \\
No & 0 \\
TRSC Scores & \\
Negligible & 0 \\
Low & $01(01)$ \\
Medium & $35(35)$ \\
High & $64(63)$ \\
Very high & $01(01)$ \\
\hline
\end{tabular}

$91 \%$ of the interviewees consider that they practice their religion, and $73 \%$ stated that the disease and treatment did not interfere with religious practices. It was observed that all used RSC, with the majority receiving a high TRSC score (Table 1 ).

The mean RSC values were: $\operatorname{TRSC}=3.67$ ( $\mathrm{sd}=0.37$ ); $\mathrm{NRSC}=1.19(\mathrm{sd}=0.26) ; \mathrm{PRSC}=2.58(\mathrm{sd}=0.67)$. The mean for the NRSC/PRSC ratio was equal to 0.21 ( $s d=0.06$ ).

\section{Associations between the RSC and the other variables studied}

Using the Spearman Correlation Coefficient, one learns that the NRSC is inversely associated with age and family income, and that the TRSC is directly associated with the importance individuals gave to religion/ spirituality and to time since diagnosis (Table 2).

Table 2 - Spearman Correlation Coefficient for the sociodemographic variables and Religious/Spiritual Coping, Minas Gerais, Brazil, 2011

\begin{tabular}{lcc}
\hline & Correlation Coefficients & $\mathbf{p}$ \\
\hline NRSC $\times$ Age & -0.209 & 0.036 \\
NRSC $\times$ Family income & -0.294 & 0.003 \\
TRSC $\times$ TD & 0.196 & 0.049 \\
TRSC x IRS & 0.307 & 0.002 \\
\hline
\end{tabular}

TD: time since diagnosis; IRS: importance of religion/spirituality.

According to analysis with the test, the women's PRSC and TRSC averages are higher than the men's. The individuals who have a religion present a negligible NRSC average. The individuals who would like to receive spiritual support have higher PRSC and TRSC averages than those who would not like to receive this support (Table 3).

Table 3 - $t$ test for the socio-demographic variables and RSC, Minas Gerais, Brazil, 2011

\begin{tabular}{|c|c|c|c|c|c|c|c|c|}
\hline \multicolumn{9}{|c|}{ Averages } \\
\hline & Sex & $p$ & HR & p & $\mathrm{Cl}$ & p & ss & $p$ \\
\hline \multirow[t]{2}{*}{ RSC P } & Male: 2.4 & 0.012 & & & Yes: 2.6 & 0.105 & Yes: 2.7 & 0.003 \\
\hline & Fem: 2.7 & 0.012 & & & No: 2.2 & 0.042 & No: 2.2 & 0.001 \\
\hline \multirow[t]{2}{*}{ RSC N } & & & Yes: 1.1 & 0.002 & & & & \\
\hline & & & No: 1.7 & 0.35 & & & & \\
\hline \multirow[t]{2}{*}{ RSC T } & Male: 3.6 & 0.04 & & & Yes: 3.7 & 0.04 & Yes: 3.7 & 0.009 \\
\hline & Fem: 3.8 & 0.04 & & & No: 3.4 & 0.03 & No: 3.5 & 0.002 \\
\hline
\end{tabular}

HR: Has religion; CI: Considers provision of spiritual care important; SS: Would like to receive spiritual support.

According to the Variance Analysis, there was statistical significance between the NRSC and the presence of side effects and the TRSC and the religious denomination (Table 4).

According to the Multiple Linear Regression Model, $17 \%$ to $26 \%$ of the variance in spirituality and religion (PRSC, NRSC and TRSC) was explained by a combination of the variables presented in Table 5. The choice of the variables was made using the backward procedure. The significant associations occurred to explain the behavior of the three types of RSC in line with the sociodemographic, clinical and religious/spiritual variables.
Table 4 - Averages for the Religious/Spiritual Coping measurements in relation to side effects and religion, Minas Gerais, Brazil, 2011

\begin{tabular}{cccc}
\hline & $\mathbf{p}$ & Side Effects & Average \\
\hline NRSC & 0.017 & None & 1.11 \\
& & Intense & 1.37 \\
\hline TRSC & 0.012 & Religion & Average \\
& & Protestantism & 3.90 \\
& & Spiritalism & 3.80 \\
& & Catholicism & 3.60 \\
& & No religion & 3.10 \\
\hline
\end{tabular}


Table 5 - Distribution of the CRE and other variables studied, according to the estimate of the parameters and

\begin{tabular}{|c|c|c|c|c|c|c|c|c|c|}
\hline & \multicolumn{3}{|c|}{ PRSC } & \multicolumn{3}{|c|}{ NRSC } & \multicolumn{3}{|c|}{ TRSC } \\
\hline & B & SE & $p$ & B & SE & $p$ & B & SE & $p$ \\
\hline SS & 0.579 & \pm 0.161 & 0.001 & - & & - & 0.198 & \pm 0.93 & 0.036 \\
\hline PG & 0.309 & \pm 0.130 & 0.019 & - & & - & 0.195 & \pm 0.68 & 0.006 \\
\hline Age & & - & - & -0.095 & \pm 0.056 & 0.094 & & - & - \\
\hline $\mathrm{HR}$ & & - & - & -0.533 & \pm 0.171 & 0.002 & 0.587 & \pm 0.229 & 0.012 \\
\hline $\mathrm{Cl}$ & & - & - & -0.225 & \pm 0.091 & 0.016 & 0.255 & \pm 0.135 & 0.063 \\
\hline Sex & & - & - & - & & - & 0.134 & \pm 0.068 & 0.054 \\
\hline TD & & - & - & - & & - & 0.140 & \pm 0.071 & 0.052 \\
\hline$R^{2}$ & & 0.173 & & & 0.195 & & & 0.263 & \\
\hline
\end{tabular}

standard errors of the multiple linear regression models, Minas Gerais, Brazil, 2011

SS: Would like to receive spiritual support; PG: Participates in support group for patients with cancer; HR: Has a religion; CI: Considers spiritual care important; TD: Time since diagnosis.

The individuals who most used PRSC are: individuals who would like to receive spiritual support and who participate in support groups for patients with cancer. Those using NRSC are younger individuals, without religion and who do not consider spiritual support important. Women, people who have received treatment for longer, participants in support groups for patients with cancer, those who would like to receive spiritual support and those who have a religion have a higher CRET.

\section{Discussion}

This study's participants used CRE in some form as a strategy for coping with the disease. Recent advances in psycho-oncology and in investigations of psycho-neuroimmunology in persons with cancer have allowed the rediscovery of the importance of spirituality in influencing the disease's clinical progression and course, in terms of support and as a variable of potential prognosis(12).

The subjects expressed that they would like to receive spiritual care (80\%) and considered approaching the issue as a way of helping in coping with the disease to be important (93\%). However, in spite of evidence in the literature on the patient's spiritual needs ${ }^{(8,13)}$, only $16 \%$ of the interviewees had received some type of spiritual support.

Without doubt, physical care predominates in nursing care, as scientificist thinking predominates in the professionals' mentality ${ }^{(14)}$. The lack of professional training(15) and the lack of theory for spiritual care are a pretext for deficiency in the same ${ }^{(16)}$. However, the Nursing Interventions Classification (NIC), which form an already-consolidated benchmark for nursing interventions propose two interventions related specifically to spirituality: Spiritual support and
Facilitation of spiritual growth(17). In implementing these interventions, nursing attends to the patient's spiritual needs ${ }^{(13)}$, forming the interface between spirituality and the profession's own body of knowledge.

The study of the relationship of the RSC with the socio-demographic aspects showed that women higher values for use of PRSC ( mean=2.7), indicating, according to the literature, that women have greater religious involvement than men(18). The data also reveals that considering religion/spirituality as something important in life $(p=0.002)$ and having a religion $(p=0.012)$ contributed significantly to use of TRSC, which backs up the assertion that, among the reasons for a positive association between religion and health is the fact that beliefs and religious practices can evoke positive emotions $^{(3)}$.

Individuals who were Evangelicals presented higher use of TRSC (mean=3.9), which may be because of the greater practice among these of religious activities (fasting, Bible reading and others) ${ }^{(4)}$. Another variable which related to TRSC was time since diagnosis, indicating that the greater this was, the greater was the use of TRSC $(p=0.049)$, as over time the number of stressors (psycho-social or physiological) with which the patient has to deal increases, which leads to greater use of ways of coping with the disease ${ }^{(19)}$. The participation in support groups for patients with cancer also presented a relationship with TRSC $(p=0.006)$ and PRSC $(p=0.019)$, which contributes to the fact that social support, among other factors, is associated with a better prognosis in cancer $^{(20)}$. The use of PRSC was also associated with the desire to receive spiritual support $(p=0.001)$, which confirms that the patients attribute an important role to spirituality, so as to minimize suffering and obtain a greater hope of being cured $^{(9)}$. 
According to the literature, values of the NRSC/PRSC ratio $\leq 0.50$ are associated with positive CRE results in quality of life ${ }^{(6)}$. The average for the NRSC/PRSC ratio found in this study was 0.21 ( $s d=0.06)$, which indicates that RSC can contribute in a positive way to a better quality of life for the participants in the research.

Low family income resulted in greater use of NRSC $(p=0.003)$. Income is strongly associated with the patient's psychological adjustment, which provides support for considering that, in addition to the human aspects involved in the health-illness process, the variables linked to the material context of people's lives also need to be investigated; at the end of the day, they provide the concrete substrate for supporting care actions ${ }^{(21)}$.

The individuals in the present study who presented intense side effects tend to use CREN the most (mean=1.37). As negative events increase, the use of strategies (both negative and positive) increases too. However, when there is no relief, but stress continues, the subjects tend to re-evaluate their understanding of God, and use negative strategies ${ }^{(5)}$. The patients with cancer are constantly submitted to invasive procedures, to the toxicity of the chemotherapy and to the pain crises caused by the disease(22). The suffering leads to a personal conflict. The patient goes through periods of anguish, anxiety and depression, in which he or she may feel "abandoned" by God and by others, and may feel incapable of praying or being consoled. Further, the patient may understand the suffering as divine punishment ${ }^{(23)}$.

The individuals with no religion but who consider themselves spiritual, presented greater use of NRSC $(p=0.002)$. This may occur through the absence of beliefs or religious practices, considering that these may evoke positive emotions ${ }^{(3)}$. Religious faith offers hope, balance and strengthening, affording a struggle for life and serenity to accept the disease ${ }^{(24)}$. The younger individuals presented a greater use of $\operatorname{NRSC}(p=0.036)$. The literature indicates that among younger subjects there is a low level of spirituality(25).

Faith may have a positive influence on the efficacy of the chemotherapy and on the clinical course of the cancer(12). Spiritual support is associated with better quality of life, but many patients' spiritual needs are not met(7). Questioning a patient about RSC, therefore, may set up a means of intervention which leads him or her to return to coping with the disease and develop this strategy's possible benefits. It is worth reiterating that spirituality can be objectively evaluated(25), thus, the instrument used in this study may be useful in clinical practice, as it is fast to use and is capable of identifying the presence of the phenomenon investigated.

Some of this study's limitations must be emphasized. The study is cross-sectional, which does not allow one to determine if the use of RSC varies according to the length of treatment undertaken; also, it was undertaken in a single center for chemotherapy treatment, so it may depict the specific experience of that locale. The carrying-out of longitudinal and multicentric research is recommended. Despite these limitations, this study's results have implications for clinical practice, considering that it offers an instrument for the inclusion of spiritual care in nursing care.

\section{Conclusion}

The study permits the conclusion that religious/ spiritual coping is an important strategy for coping with cancer. The results also indicate that the patients with cancer who are undergoing chemotherapy treatment are religious, that they consider spirituality/religion to be important in their lives, and that they would like health professionals to address this issue by offering spiritual care.

The identification of the use of Religious/Spiritual Coping as a strategy for coping with the disease by the population under study contributes to the planning of interventions related to religiosity/spirituality. The identification of the profile of the subjects who use Religious/Spiritual Coping makes it easier for the nurse to select the nursing care interventions which are appropriate for each type of patient. In this way, the scale becomes a useful instrument for carrying out spiritual care.

\section{References}

1. Stroppa A, Moreira-Almeida A. Religiosidade e Saúde. In: Salgado MI, Freire G. Saúde e Espiritualidade: uma nova visão da medicina. Belo Horizonte (MG): Inede; 2008. p. 427-43.

2. Como J. Spiritual practice: a literature review related to spiritual health and health outcomes. Holistic Nurs Pract. 2007;21(5):224-36.

3. Panzini RG, Bandeira DR. Spiritual/religious coping. Rev Psiq Clín. 2007;34(1):126-35.

4. Mellagi AG. Religious coping in HIV/SIDA patients: a psychosocial study among Catholic and Pentecostal men [dissertação de mestrado]. São Paulo (SP): Instituto de Psicologia da Universidade de São Paulo; 2009. 84 p.

5. Pargament KI, Koenig HG, Perez LM. The many methods 
of religious coping: Development and initial validation of the RCOPE. J Clin Psychol. 2000;56(4):519-43.

6. Panzini RG, Bandeira DR. Spiritual/Religious Coping Scale (Srcope Scale): elaboration and construct validation. Psicol Estud. 2005;10(3):507-16.

7. Balboni TA, Vanderwerker LC, Block SD, Paulk ME, Lathan CS, Peteet JR, et al. Religiousness and spiritual support among advanced cancer patients and associations with end-of-life treatment preferences and quality of life. J Clin Oncol. 2007;25(5):555-60.

8. Travado L, Grassi L, Gil F, Martins C, Ventura C, Bairradas $\mathrm{J}$ et al. Do spirituality and faith make a difference? Report from the Southern European PsychoOncology Study Group. Palliative Supportive Care. 2010;8(4):405-413.

9. Guerrero GP, Zago MMF, Sawada NO, Pinto MH. Relationship between spirituality and cancer: patient's perspective. Rev Bras Enferm. 2011;64(1):53-9.

10. Moreira-Almeida A, Lotufo Neto F, Koenig HG. Religiousness and mental health: a review. Rev Bras Psiquiatr. 2006;28(3):242-50.

11. Panzini RG, Maganha C, Rocha NS, Bandeira DR, Fleck MP. Brazilian validation of the Quality of Life Instrument/spirituality, religion and personal beliefs. Rev Saude Publica. 2011;45(1):153-65.

12. Lissoni $P$, Messina G, Parolini D, Balestra A, Brivio F, Fumagalli $L$, et al. A spiritual approach in the treatment of cancer: relation between faith score and response to chemotherapy in advanced non-small cell lung cancer patients. In vivo. 2008;22(5):577-82.

13. Sartori P. Spirituality 1: Should spiritual and religious beliefs be part of patient care? Nurs Times. 2010;106(28):14-7.

14. Espíndula JA, Valle ERM, Bello AA. Religion and spirituality: the perspective of health professionals. Rev. Latino-Am. Enfermagem. 2010;18(6):1229-36.

15. Pedrão RB, Beresin R. Nursing and spirituality. Einstein. 2010;8(1 Pt 1):86-91.

16. Penha RM, Silva MJP. Knowledge and perception on the importance of the spiritual dimension of care by Nursing Undergraduate Students. O Mundo da Saúde. 2007;31(2):238-45.

17. Bulechek GM, Butcher HK, Dochterman JM. NIC: Nursing Interventions Classification. 5 ed. Rio de Janeiro: translator. Rio de Janeiro: Elsevier; 2010.

18. Moreira-Almeida A, Pinsky I, Zaleski M, Laranjeira R. Religious involvement and sociodemographic factors: a Brazilian national survey. Rev Psiq Clín. 2010;37(1):12-5. 19. Bertolin DC. Ways of coping of the people with terminal chronic renal failure in hemodialysis treatment [dissertação de mestrado]. Ribeirão Preto (SP): Escola de Enfermagem de Ribeirão Preto da Universidade de São Paulo; 2007. 141 p.

20. Falagas ME, Zarkadoulia EA, Ioannidou EM, Peppas G, Christodoulou C, Rafailidis PI. The effect of psychosocial factors on breast cancer outcome: a systematic review. Breast Cancer Res. 2007;9(4):1-23.

21. Mastropietro AP, Oliveira-Cardoso EA, Simões BP, VoltarelliI JC, Santos MA. Relationship between income, work and quality of life of patients submitted to bone marrow transplantation. Rev Bras Hematol Hemoter. 2010;32(2):102-7.

22. Jaconodino CB, Amestoy SC, Thofehrn MB. Alternative therapies for patients undergoing chemotherapy. Cogitare Enferm. 2008;13(1):61-6.

23. Yunta ER. El sentido del sufrimiento: experiencia de los enfermos de cáncer. Ars Med. (Santiago). 2000;2(3):73-88.

24. Teixeira JJV, Lefèvre F. The meaning of medical intervention and religious faith for the elderly cancer patient. Cienc Saúde Coletiva. 2008;13(4):1247-56.

25. Pillon SC, Santos MA, Gonçalves AMS, Araújo KM. Alcohol use and spirituality among nursing students. Rev Esc Enferm USP. 2011;45(1):100-7. 